\title{
Pelvic endometriosis: reproductive and menstrual risk factors at different stages in Lombardy, northern Italy
}

Fabio Parazzini, Monica Ferraroni, Luigi Fedele, Luca Bocciolone, Sabrina Rubessa, Aldo Riccardi

\begin{abstract}
Aim - To analyse the relationship between reproductive and menstrual factors and different stages of pelvic endometriosis. Methods - Between 1987 and 1990 a casecontrol study of risk factors for pelvic endometriosis was conducted. Cases comprised 376 women (median age 32 years) with pelvic endometriosis confirmed by laparoscopy or laparotomy admitted to any one of three clinics in Lombardy, northern Italy. A total of $129(34 \cdot 3 \%)$ of these women were at stage $1,76(20 \cdot 2 \%)$ at stage $2,96(25 \cdot 5 \%)$ at stage 3 , and 75 (19.9\%) at stage 4 , according to the American Fertility Society revised classification of endometriosis. Controls comprised 522 women admitted to hospital for acute conditions.
\end{abstract}

Results - The risk of endometriosis decreased with increasing number of births. The estimated odds ratios (OR) were similar in different stages of the disease: for example, compared with nulliparous women, the OR of endometriosis at stage 1 was $0 \cdot 1$ in women who reported two or more births and the corresponding values were respectively $0 \cdot 1,0.2$, and 0.2 for endometriosis at stages 2,3 , and 4 . Cases reported fewer induced abortions than controls: the estimated ORs compared with no induced abortion were $0.4,0.5$, 0.2 , and 0.2 in women who reported one or more induced abortions for subsequent stages of endometriosis. Women with irregular menstrual cycles were at less risk of the disease: compared with women who reported lifelong regular cycles the estimated ORs were $0.3,0.5,0.5$, and 0.3 for disease stages 1-4 respectively. No consistent association emerged between the ages at menarche and at first delivery and the risk of endometriosis.

Conclusions - This analysis provides further evidence that reproductive and menstrual factors are associated with the risk of endometriosis. The observation that early and late stages of the disease share similar epidemiological characteristics suggests an epidemiological (and pathogenetic) continuum between various stages of the disease.

( $\mathcal{F}$ Epidemiol Community Health 1995;49:61-64)
Whether mild and advanced endometriosis are a continuum of the same disease or two different aetiopathogenic and clinical conditions has been debated. Furthermore, the importance of mild lesions as a pathological or paraphysiological condition has been discussed. ${ }^{1}$ In epidemiological terms, if these lesions are part of a continuum, they should share common characteristics.

Although there is some evidence that nulliparity and menstrual characteristics such as a lifelong regular menstrual pattern and early menarche increase the risk of peritoneal and ovarian endometriosis, ${ }^{2-4}$ no epidemiological study has considered separately the risk factors for endometriosis in mild or severe disease. We have analysed information from a case-control study on risk factors for endometriosis conducted in northern Italy.

\section{Methods}

Between 1987 and 1990 we conducted a casecontrol study on risk factors for pelvic endometriosis. The design of this study has already been described. ${ }^{4}$

\section{CASES}

Cases were 376 women (median age 32 years) with pelvic endometriosis (confirmed by laparoscopy or laparotomy) admitted to the $\mathrm{Ob}-$ stetrics and Gynecology Clinic Luigi Mangiagalli of Milan and (in the period 198788) to the Obsterics and Gynecology Clinics of Brescia and Pavia, three neighbouring cities in Lombardy, in northern Italy. The distribution of cases in relation to the stage and site of the disease and indications for diagnostic surgery is shown in table 1 . Of the cases, 129 $(34 \%)$ were at stage $1,76(20 \%)$ at stage 2,96 $(26 \%)$ at stage 3 , and $75(20 \%)$ at stage 4 , according to the 1985 American Fertility Society revised classification. A total of 132 subjects had ovarian endometriosis, 120 had peritoneal lesions, and 123 had both ovarian and peritoneal disease. The indication for diagnostic surgery was infertility in 122 cases (33\%), pelvic pain in $52(14 \%)$, pelvic masses in $90(24 \%)$, and in 110 cases (29\%) diagnosis was incidental at the time of other procedures such as hysterectomy for fibroids (in two cases information was missing). For the purposes of this analysis, the pelvic mass and incidental diagnosis groups, which include conditions not related to specific symptoms of endometriosis, were considered together. 
Table 1 Distribution of cases with endometriosis in relation to stage, site of the disease, and indication for surgery. Lombardy, Italy, 1987-90

\begin{tabular}{|c|c|c|c|c|}
\hline & \multicolumn{4}{|c|}{ Disease stage } \\
\hline & $\begin{array}{l}1 s t \\
\text { No (\%) }\end{array}$ & $\begin{array}{l}\text { 2nd } \\
\text { No (\%) }\end{array}$ & $\begin{array}{l}3 r d \\
\text { No (\%) }\end{array}$ & $\begin{array}{l}4 t h \\
\text { No (\%) }\end{array}$ \\
\hline $\begin{array}{l}\text { Site of the disease: } \\
\text { Ovary } \\
\text { Peritoneum } \\
\text { Ovary and peritoneum }\end{array}$ & $\begin{array}{ll}24 & (19) \\
89 & (69) \\
16 & (12)\end{array}$ & $\begin{array}{l}15(20) \\
26(34) \\
35(46)\end{array}$ & $\begin{array}{r}63(66) \\
4(9) \\
29(31)\end{array}$ & $\begin{array}{rr}30 & (40) \\
2 & (3) \\
43 & (57)\end{array}$ \\
\hline $\begin{array}{l}\text { Indication for surgery: } \\
\text { Infertility } \\
\text { Pelvic pain } \\
\text { Other }\end{array}$ & $\begin{array}{lc}66^{*} & (52) \\
24 & (19) \\
38 & (30)\end{array}$ & $\begin{array}{l}37(49) \\
15(20) \\
24(32)\end{array}$ & $\begin{array}{rr}8 & (8) \\
9 & (9) \\
79 & (82)\end{array}$ & $\begin{array}{rr}11^{*} & (15) \\
4 & (5) \\
59 & (80)\end{array}$ \\
\hline
\end{tabular}

*In two cases the information on indication for surgery was missing.

Table 2 Distribution of cases of endometriosis and controls in relation to age, education, marital status, and stage of the disease. Lombardy, Italy, 1987-90

\begin{tabular}{|c|c|c|c|c|c|}
\hline & \multicolumn{4}{|c|}{ Disease stage } & \multirow{2}{*}{$\begin{array}{l}\text { Controls } \\
\text { No (\%) }\end{array}$} \\
\hline & $\begin{array}{l}1 s t \\
\text { No (\%) }\end{array}$ & $\begin{array}{l}\text { 2nd } \\
\text { No (\%) }\end{array}$ & $\begin{array}{l}3 r d \\
\text { No (\%) }\end{array}$ & $\begin{array}{l}4 \text { th } \\
\text { No (\%) }\end{array}$ & \\
\hline $\begin{array}{c}\text { Age (y): } \\
\leq 24 \\
25-29 \\
30-34 \\
35-39 \\
40-44 \\
\geq 45\end{array}$ & $\begin{array}{rr}20 * & (16) \\
35 & (27) \\
45 & (35) \\
13 & (10) \\
9 & (7) \\
7 & (5)\end{array}$ & $\begin{array}{r}7(9) \\
19(25) \\
30(39) \\
8(11) \\
7(9) \\
5(7)\end{array}$ & $\begin{array}{r}7(7) \\
24(25) \\
21(22) \\
15(16) \\
18(19) \\
11(11)\end{array}$ & $\begin{array}{r}9(12) \\
16(21) \\
26(35) \\
9(12) \\
12(16) \\
3(4)\end{array}$ & $\begin{array}{r}101(19) \\
72(14) \\
117(22) \\
109(21) \\
67(13) \\
56(11)\end{array}$ \\
\hline $\begin{array}{l}\text { Marital status: } \\
\text { Married } \\
\text { Never married }\end{array}$ & $\begin{aligned} 100 & (78) \\
29 & (22)\end{aligned}$ & $\begin{array}{l}57(75) \\
19(25)\end{array}$ & $\begin{array}{l}73(76) \\
23(24)\end{array}$ & $\begin{array}{l}48(64) \\
27(36)\end{array}$ & $\begin{array}{l}336(64) \\
186(36)\end{array}$ \\
\hline $\begin{array}{l}\text { Education: } \\
\quad<7 \\
7-11 \\
\geq 12\end{array}$ & $\begin{array}{ll}10 & (8) \\
51 & (40) \\
66 & (52)\end{array}$ & $\begin{array}{l}10(13) \\
24(32) \\
42(55)\end{array}$ & $\begin{array}{r}5(5) \\
38(40) \\
52(55)\end{array}$ & $\begin{array}{r}8(11) \\
15(20) \\
52(69)\end{array}$ & $\begin{array}{l}130(25) \\
203(39) \\
186(36)\end{array}$ \\
\hline
\end{tabular}

* In some cases the individual values do not add up to the total because of missing values.

\section{CONTROLS}

Controls were women admitted on randomly selected days for acute conditions to the Ospedale Maggiore of Milan (which includes the four largest hospitals in Milan) and to the hospitals in which the cases had been identified in Pavia and Brescia. Although the 1st $\mathrm{Ob}$ stetrics and Gynecology Clinic of the University of Milan is not administratively part of the Ospedale Maggiore of Milan, it is close to that hospital and covers a comparable catchment area. Women admitted for gynaecological, hor- monal, metabolic, or neoplastic diseases, or those who had undergone hysterectomy or unilateral or bilateral oophorectomy were specifically excluded from the comparison group. Controls were interviewed in the month after the case identification. They were the first two elegible subjects identified at the time of the interviewer's visit.

Cases and controls were not individually matched, but the comparison group was comparable with cases in terms of quinquennia of age and hospital. Altogether 522 controls (median age 33 years) were interviewed. Of these, $32 \%$ were admitted for traumatic conditions (mostly fractures and sprains), $32 \%$ had non-traumatic orthopaedic disorders (mostly low back pain and disc disorders), $18 \%$ had surgical conditions (mostly abdominal such as acute appendicitis or strangulated hernia), and $17 \%$ had other illnesses, such as ear, nose, throat, or dental disorders. No specific programme of investigation was done to rule out endometriosis in controls. Less than $3 \%$ of eligible women refused to be interviewed.

Trained interviewers identified and questioned cases and controls using a standard questionnaire which included items on general characteristics, lifestyle habits, and reproductive and menstrual factors.

DATA ANALYSIS

We computed the odds ratios (OR) for different stages of endometriosis from data stratified for quinquennia of age by the Mantel-Haenszel procedure. ${ }^{5}$ For dichotomous variables, the significance of estimates is given by the $95 \%$ confidence interval (CI) of the ratio. ${ }^{6}$ When a factor could be classified in more than two levels, the significance of the linear trend was assessed by the Mantel test. ${ }^{7}$ In an attempt to minimise and analyse the effect of selection and detection bias, we computed age adjusted

Table 3 Odds ratio of endometriosis (adjusted for age) according to the stage of the disease and selected reproductive and menstrual factors. Lombardy, Italy, 1987-90. (The reference category is in bold type)

\begin{tabular}{|c|c|c|c|c|c|c|}
\hline & \multicolumn{5}{|l|}{ Disease stage } & \multirow[t]{2}{*}{ Controls } \\
\hline & Total & $1 s t$ & $2 n d$ & $3 r d$ & $4 t h$ & \\
\hline $\begin{array}{c}\text { Parity: } \\
0 \\
1 \\
\geq 2 \\
\chi_{1}^{2} \text { trend }\end{array}$ & $\begin{array}{r}1 \\
0.4 \\
0.2 \\
30.3(p<0.01)\end{array}$ & $\begin{array}{r}1(103)^{*} \\
0.3(18) \\
0.1(8) \\
70.0(p<0.01)\end{array}$ & $\begin{array}{r}1(60) \\
0 \cdot 1(6) \\
0 \cdot 1(10) \\
96 \cdot 7(\mathrm{p}<0 \cdot 01)\end{array}$ & $\begin{array}{r}1(59) \\
0.4(16) \\
0 \cdot 2(20) \\
23.3(\mathrm{p}<0.01)\end{array}$ & $\begin{array}{r}1(51) \\
0.3(10) \\
0 \cdot 2(14) \\
20.9(p<0.01)\end{array}$ & $\begin{array}{l}(218) \\
(117) \\
(187)\end{array}$ \\
\hline $\begin{array}{l}\text { Spontaneov } \\
0 \\
\geq 1\end{array}$ & $\begin{array}{r}1 \\
0.7 \\
(0 \cdot 4,1 \cdot 2)\end{array}$ & $\begin{array}{r}1(112) \\
1 \cdot 1(17) \\
(0 \cdot 6,1 \cdot 9)\end{array}$ & $\begin{array}{r}1(68) \\
0.5(8) \\
(0.2,1.3)\end{array}$ & $\begin{array}{r}1(84) \\
0 \cdot 7(11) \\
(0 \cdot 3,1 \cdot 4)\end{array}$ & $\begin{array}{r}1(69) \\
0.5(6) \\
(0.2,1 \cdot 2)\end{array}$ & $\begin{array}{r}(447) \\
(75)\end{array}$ \\
\hline $\begin{array}{c}\text { Induced ab } \\
0 \\
\geq 1\end{array}$ & $\begin{array}{r}1 \\
0.4 \\
(0 \cdot 2,0 \cdot 8)\end{array}$ & $\begin{array}{r}1(121) \\
0.4(8) \\
(0.2,0.9)\end{array}$ & $\begin{array}{r}1(70) \\
0 \cdot 5(6) \\
(0 \cdot 2,1 \cdot 1)\end{array}$ & $\begin{array}{r}1(91) \\
0 \cdot 2(4) \\
(0 \cdot 1,0 \cdot 7)\end{array}$ & $\begin{array}{r}1(73) \\
0 \cdot 2(2) \\
(0 \cdot 1,0 \cdot 5)\end{array}$ & $\begin{array}{r}(442) \\
(80)\end{array}$ \\
\hline $\begin{array}{c}\text { Age at first } \\
\leq 24 \\
25-29 \\
\geq 30 \\
\chi^{2}{ }_{1} \text { trend }\end{array}$ & $\begin{array}{r}1 \\
1.5 \\
1.2 \\
0.29(p=N S)\end{array}$ & $\begin{array}{r}1(12) \\
2.3(13) \\
0.5(1) \\
0.40(p=N S)\end{array}$ & $\begin{array}{r}1(8) \\
\\
1.2(7) \\
1.4(1) \\
0.0 \quad(p=N S)\end{array}$ & $\begin{array}{r}1(17) \\
1.6(16) \\
1.6(3) \\
0.20(p=N S)\end{array}$ & $\begin{array}{r}1(13) \\
0.9(7) \\
1.4(4) \\
0.21(\mathrm{p}=\mathrm{NS})\end{array}$ & $\begin{array}{r}(178) \\
(96) \\
(29)\end{array}$ \\
\hline $\begin{array}{l}\text { Age at men } \\
\leq 11 \\
12-13 \\
\geq 14 \\
\chi^{2}{ }_{1} \text { trend }\end{array}$ & $\begin{array}{r}1 \\
0.8 \\
0.9 \\
0.24(p=N S)\end{array}$ & $\begin{array}{r}1 \text { (34) } \\
0.9(59) \\
1.0(33) \\
0.0 \quad(\mathrm{p}=\mathrm{NS})\end{array}$ & $\begin{array}{r}1(24) \\
0.6(31) \\
0.8(21) \\
0.61 \text { ( } \mathrm{p}=\text { NS) }\end{array}$ & $\begin{array}{r}1(20) \\
1.3(53) \\
0.9(22) \\
0.10(\mathrm{p}=\mathrm{NS})\end{array}$ & $\begin{array}{r}1(22) \\
0.9(38) \\
0.6(15) \\
0.23(\mathrm{p}=\mathrm{NS})\end{array}$ & $\begin{array}{l}(132) \\
(251) \\
(139)\end{array}$ \\
\hline $\begin{array}{c}\text { Lifelong m } \\
\text { Regular } \\
\text { Irregular }\end{array}$ & $\begin{array}{r}1 \\
0.4 \\
(0 \cdot 2,0 \cdot 8)\end{array}$ & $\begin{array}{r}1(120) \\
0 \cdot 3(7) \\
(0 \cdot 2,0 \cdot 7)\end{array}$ & $\begin{array}{r}1(68) \\
0.5(6) \\
(0 \cdot 2,1 \cdot 2)\end{array}$ & $\begin{array}{r}1(88) \\
0.5(7) \\
(0.2,1.0)\end{array}$ & $\begin{array}{r}1(71) \\
0 \cdot 3(4) \\
(0 \cdot 1,0 \cdot 9)\end{array}$ & $\begin{array}{r}(445) \\
(77)\end{array}$ \\
\hline
\end{tabular}

Number of subjects is shown in parentheses. In some cases the sum of individual values is not the same as the total because of missing values. 
ORs for the total series and according to the indication for surgery (sterility, pelvic pain, and other reasons including pelvic masses or incidental diagnosis).

With the sample size of this study we were able to identify ORs of about 0.5 for factors with a prevalence of about $15 \%$ in the control group (such as history of spontaneous abortion or induced abortion) and of about 1.5 for factors with a prevalence of about $25-30 \%$ with the usual values of $\alpha=0.05$ and $\beta=0 \cdot 20{ }^{8}$ The power is of course lower when analysis was performed in strata of stages of the disease. In this analysis the level of statistical significance was always $0 \cdot 05$.

\section{Results}

Table 2 shows the distribution of cases and controls in relation to the stage of the disease, age, marital status, and education. Cases with endometriosis tended to be better educated and were more frequently married. For example, the percentage of never married women ranged from $22-25 \%$ in cases at stages 1 to 3, but was $36 \%$ in cases at stage 4 and in controls. Likewise, the percentage of who reported fewer than seven years of schooling ranged from 5$11 \%$ in the four stages of endometriosis, but was $25 \%$ in controls.

The ORs of endometriosis for different stages according to selected reproductive and menstrual factors are presented in table 3 . The risk of the disease decreased with the number of births. The estimated ORs were consistent at different stages of the disease. For example, compared with nulliparous women, the OR of endometriosis at stage 1 was $0 \cdot 1$ (95\% CI $0 \cdot 1$, $0 \cdot 2$ ) in women reporting two or more births and respectively $0 \cdot 1(95 \% \mathrm{CI} 0 \cdot 1,0 \cdot 3), 0 \cdot 2$ $(95 \%$ CI $0 \cdot 1,0 \cdot 4)$, and $0.2(95 \%$ CI $0 \cdot 1,0.4)$ for endometriosis at stages 2,3 , and 4 . Cases less frequently reported induced abortions than controls. The estimated ORs in comparison with no induced abortion were $0.4(95 \% \mathrm{CI}$ $0.2,0.9), 0.5(95 \%$ CI $0.2,1 \cdot 1), 0.2(95 \% \mathrm{CI}$ $0 \cdot 1,0 \cdot 7)$, and $0.2(95 \% \mathrm{CI} 0 \cdot 1,0.5)$ in women who reported one or more induced abortions for stages 1-4 respectively. Likewise, cases reported spontaneous abortions less frequently, but the estimated ORs were not statistically significant.
Women with irregular menstrual cycles were at a lower risk of the disease. Compared with those who reported lifelong regular cycles, the estimated ORs were $0.3(95 \%$ CI $0.2,0.7), 0.5$ (95\% CI $0.2,1.2), 0.5(95 \%$ CI $0.2,1.0)$, and $0.3(95 \%$ CI $0.1,0.9)$ respectively for subsequent disease stages. These estimates were statistically significant for stages 1,3 , and 4. No consistent association emerged between the age at first delivery, age at menarche, and the risk of endometriosis.

The role of factors found to be significantly associated with the risk of endometriosis was also analysed in relation to indications for surgery (table 4 ). In these analyses early (1st and 2nd) and late (3rd and 4th) stages were pooled together because of the limited numbers of subjects in various strata. The estimated ORs were largely consistent for early and late stages in subgroups of indication for diagnostic surgery. In this table "pelvic masses" or "incidental diagnosis of endometriosis" were pooled together, since these two clinical situations should be less affected by selection biases. In fact all women with pelvic masses underwent surgery without any positive or negative selective mechanisms associated with suspicions of endometriosis. Furthermore, the estimated ORs were largely consistent when an exploratory analysis was performed that considered separately women with pelvic masses or an incidental diagnosis of endometriosis. For example, the estimated ORs for induced abortions were 0.2 for both early ( $95 \%$ CI $0 \cdot 1,0.4)$ and late stages $(95 \%$ CI $0 \cdot 1,0.3)$ in the two subgroups and the ORs for an early stage of endometriosis were $0.4(95 \% \mathrm{CI} 0.1,0.7)$ and $0.5(95 \%$ CI $0.3,0.8)$ respectively in women with pelvic masses or incidental diagnosis for an irregular lifetime menstrual pattern. The respective values were $0.4(95 \% \mathrm{CI} 0.2,0.7)$ and $0.5(95 \%$ CI $0.2,0.8)$ for late stages.

\section{Discussion}

This study confirms, in a large data set, that risk of endometriosis is increased in nulliparous women and in those with a lifelong regular menstrual pattern. Induced abortion was less frequently reported among cases than controls, too. These findings were consistent when the

Table 4 Odds ratios (adjusted for age) of endometriosis according to selected reproductive and menstrual factors, stage of the disease, and the indication for surgery. Lombardy, Italy. (Reference category is in bold type)

\begin{tabular}{|c|c|c|c|c|c|c|}
\hline & \multicolumn{2}{|l|}{ Infertility } & \multicolumn{2}{|l|}{ Pelvic pain } & \multicolumn{2}{|r|}{ Other } \\
\hline & $\begin{array}{r}\text { Stage } \\
\text { 1st-2nd }\end{array}$ & $\begin{array}{r}\text { Stage } \\
\text { 3rd-4th }\end{array}$ & $\begin{array}{r}\text { Stage } \\
1 s t-2 n d\end{array}$ & $\begin{array}{r}\text { Stage } \\
3 r d-4 t h\end{array}$ & $\begin{array}{r}\text { Stage } \\
\text { 1st-2nd }\end{array}$ & $\begin{array}{r}\text { Stage } \\
3 r d-4 t h\end{array}$ \\
\hline \multicolumn{7}{|l|}{ Parity: } \\
\hline $\begin{array}{l}0 \\
\geq 1\end{array}$ & $\begin{array}{r}1(99) \\
0 \cdot 1(4) \\
(0 \cdot 0-0 \cdot 1)\end{array}$ & 1 (19) & $\begin{array}{r}1(24) \\
0.4(15) \\
(0 \cdot 2-0.9)\end{array}$ & $\begin{array}{r}1(9) \\
0.3(4) \\
(0.0-0.9)\end{array}$ & $\begin{array}{r}1(39) \\
0 \cdot 4(23) \\
(0 \cdot 3-0 \cdot 8)\end{array}$ & $\begin{array}{r}1(82) \\
0.5(56) \\
(0 \cdot 3-0 \cdot 7)\end{array}$ \\
\hline \multicolumn{7}{|c|}{ Induced abortion: } \\
\hline $\begin{array}{l}0 \\
\geq 1 \\
\text { Lifelong men }\end{array}$ & $\begin{array}{r}1(96) \\
0 \cdot 4(7) \\
(0 \cdot 2-0 \cdot 9)\end{array}$ & $\begin{array}{r}1(17) \\
0 \cdot 6(2) \\
(0 \cdot 1-2 \cdot 5)\end{array}$ & $\begin{array}{r}1(34) \\
0 \cdot 9(5) \\
(0 \cdot 3-2 \cdot 6)\end{array}$ & $\begin{array}{l}1(13) \\
-(-)\end{array}$ & $\begin{array}{r}1(60) \\
0 \cdot 2(2) \\
(0 \cdot 1-0 \cdot 7)\end{array}$ & $\begin{array}{r}1(134) \\
0 \cdot 2(4) \\
(0 \cdot 1-0 \cdot 4)\end{array}$ \\
\hline $\begin{array}{l}\text { Lifelong men } \\
\text { Regular } \\
\text { Irregular }\end{array}$ & $\begin{array}{r}1(96) \\
-(5) \\
(0 \cdot 1-0 \cdot 8)\end{array}$ & $\begin{array}{r}1(16) \\
0 \cdot 6(3) \\
(0 \cdot 1-2 \cdot 5)\end{array}$ & $\begin{array}{r}1(35) \\
0 \cdot 5(3) \\
(0 \cdot 2-1 \cdot 7)\end{array}$ & $\begin{array}{l}1(13) \\
-(-)\end{array}$ & $\begin{array}{r}1(56) \\
0 \cdot 5(5) \\
(0 \cdot 2-1 \cdot 3)\end{array}$ & $\begin{array}{r}1(130) \\
0.4(8) \\
(0 \cdot 2-0.8)\end{array}$ \\
\hline
\end{tabular}
Number of cases is shown in parentheses. In some cases the sum of individual values is not the same as total because of missing
values. 
analysis considered the four stages of the disease separately.

Before discussing our results, potential biases should be carefully considered. Stage classification was based on information provided on surgical forms, the accuracy of which was not formally evaluated. Misclassification might tend to reduce differences between stages; however, all surgery was performed under the supervision of a senior researcher, and the first and the fourth stages represent two different conditions. No specific investigative programme (that is, laparoscopy or surgery) was undertaken in controls to rule out endometriosis, so we do not know whether or not they had it. However, the proportion of women with undiagnosed endometriosis should be low (comparable with that in the general population) and, in any case, the presence of women with endometriosis (potential cases) in the control group would not explain the differences observed, as this would tend to reduce the differences in the epidemiological characteristics of the two groups. Infertility and pelvic pain are clinical findings in endometriosis, and are often the reason for diagnostic procedures. This selective mechanism raises the frequency of infertile women among the cases. In order to take this bias into account, we analysed data for different subgroups in relation to the indication for surgery. Furthermore, this selection bias may also act more noticeably in the early stages of endometriosis. For example, in this analysis the 4 th stage is more represented in the "other" diagnostic group (that is, incidental finding or pelvic mass) than in infertility or pelvic pain groups. Although our study included about 400 cases with endometriosis, numbers analysed in specific subgroups were limited; however the OR estimates for different stages and indications for surgery were so similar in the different subgroups that we believe this provides strong evidence for the consistency of the general results. Specifically, parity had a protective effect for all the stages in women who had surgery not only for infertility, but also for pelvic pain or other conditions.

In relation to other potential sources of bias, cases and controls were identified in institutions that covered broadly comparable catchment areas and participation was almost complete. Furthermore, allowance for potential confounding factors did not change appreciably the estimated OR. Information bias can hardly have much effect on variables such as obstetric history, and cases should not tend to report menstrual irregularities less frequently than controls (in fact, more accurate recall might be expected from the cases, leading to an underestimate of the actual difference. ${ }^{9}$

There is some evidence than endometriosis is associated with nulliparity and a lifelong regular menstrual pattern. ${ }^{2-4}$ These factors seem to act similarly on the risk of peritoneal and ovarian disease. ${ }^{4}$ Less clear is the relation with age at menarche. Age at menarche was earlier in cases with endometriosis than in controls in a case-control study conducted in the USA on more than 250 cases and about 3500 controls, ${ }^{3}$ but no significant association between age at menarche and ovarian endometriotic cysts was reported in an Italian study. ${ }^{10}$

No difference was observed in the history of a regular lifelong menstrual pattern between women with different stages of endometriosis in a large analysis of menstrual symptoms in women with endometriosis, " suggesting that early and late disease may show similar epidemiological menstrual characteristics. The present study confirms this finding.

In conclusion, this analysis provides further evidence that reproductive and menstrual factors are associated with the risk of endometriosis. The observation that early and late stages of the disease share similar epidemiological characteristics suggests an epidemiological (and pathogenetic) continuum between the various stages.

This work was conducted within the framework of the CNR (Italian National Research Council) applied project, Prevention and Control of Disease Factors. Ms Judy Baggott, Ivana Garimoldi, and the GA Pfeiffer Memorial Library Staff provided helpful editorial assistance.

1 Wheeler JM, Malinak LR. Does mild endometriosis cause infertility? Seminars in Reproductive Endocrinology 1988;6: $239-49$

2 Houston DE. Evidence for the risk of pelvic endometriosis by age, race and socieconomic status. Epidemiol Rev 1984 6:167-91.

3 Cramer DW, Wilson E, Stillman RJ, et al. The relation of endometriosis to menstrual characteristics, smoking, and exercise. $\mathcal{F A M A}$ 1986;255:1904-8.

4 Candiani GB, Parazzini F, Danesino V, et al. Reproductive and menstrual factors and risk of peritoneal and ovarian endometriosis. Fertil Steril 1991;56:230-4.

5 Mantel N, Haenszel W. Statistical aspects of the analysis of data from retrospective studies of disease. $\mathcal{F}$ Natl Cancer Inst 1959;22:719-48.

6 Miettinen O. Estimability and estimation in case-referrent studies. Am $\mathcal{F}$ Epidemiol 1976;103:226-35.

studies. Am f Epidemiol 1976;103:226-35.
Mantel N. Chi-square tests with one degree of freedom. Extensions of the Mantel-Haenszel procedure. $7 \mathrm{Am}$ Stat Assoc 1963;58:690-700.

8 Walter SD. Determination of significant relative risks and optimal sampling procedures in prospective and retrospective comparative studies of various sizes. $\mathrm{Am} f$ Epidemiol 1977;105:387-97.

9 Bean JA, Leeper JD, Wallace RB, et al. Variations in the reporting of menstrual histories. Am 7 Epidemiol 1979 109:181-5

10 Parazzini F, La Vecchia C, Franceschi S, et al. Risk factors for endometrioid, mucinous and serous benign ovarian cysts. Int 7 Epidemiol 1989;18:108-12.

11 Mahmood TA, Templeton AA, Thomson L, et al. Menstrua symptoms in women with pelvic endometriosis. $\mathrm{Br} \mathcal{F} \mathrm{Obstet}$ Gynaecol 1991;98:558-63. 